\title{
Experimental Study on the Influence of Fly Ash on Mechanical Properties and Shrinkage Performance of Concrete
}

\author{
Yongning CUI \\ Jiangsu New Head Line Development Group Co., Ltd. \\ Lianyungang, China \\ e-mail: 793886686@qq.com
}

\author{
Xiaoxia WU \\ Zhengzhou College of Traffic Technicians \\ Zhengzhou, China \\ e-mail:877950010@qq.com
}

\author{
Qingfu LI \\ College of Water Conservancy and Environment \\ Engineering \\ Zhengzhou University \\ Zhengzhou, China \\ e-mail: lqflch@zzu.edu.cn
}

\author{
Ying MA \\ College of Water Conservancy and Environment \\ Engineering \\ Zhengzhou University \\ Zhengzhou, China \\ e-mail: 1447845939@qq.com
}

\begin{abstract}
Fly ash is a commonly used concrete admixture, which can improve its durability. In this paper, a series of experiments were made to study the influence of the amount of fly ash additive on the mechanical properties and shrinkage properties of concrete, which provides reference for the preparation of fly ash concrete. The results proved that the mixing of fly ash can improve the strength of concrete, restrain the production of concrete shrinkage cracks, and the fly ash plays a role in the late stage of concrete strength growth.
\end{abstract}

Keywords-fly ash; concrete strength; elasticity modulus; shrinkage performance of concrete

\section{INTRODUCTION}

Fly ash is a kind of industrial waste, the problem of accumulation and pollution of fly ash could be solved, and better social and economic benefits could be obtained when it is used as admixture of concrete. Replacing part of cement with fly ash in the mixture of concrete, we can reduce the concrete's cost; improve its physical mechanics properties and its durability. It has been shown that fly-ash concrete has a better long-term performance than ordinary concrete relying on the site investigation of the fly ash engineering structure which was used for more than ten years conducted By Yue-hong han et al. The effect of different fly ash content on shrinkage of concrete was studied by Zhang Xiaowei et al., Tongji University [3]. And the test results showed that addition of fly ash has not an obvious shrinkage reducing efficiency, and when the quality of fly ash replacement rate was 20\% 30\%, it has little effect on shrinkage. Qiao Fengjiao has did the drying shrinkage of HPC (high performance concrete) [4] through complex doped calcium-enriched powders and fly ash, admixture zeolite powder and fly ash, calcium-adding fly ash and fly ash. composite doped increasing calcium fly ash and fly ash high performance concrete dry shrinkage experiments, he thought that drying shrinkage of HPC with zeolite powder and fly ash would be increased with the zeolite powder replacement of fly ash Reasonable content of fly ash in concrete beam was deemed to be from $30 \% \sim 40 \%$ according to the research conducted in 2014 by Huang Bo [5]. More and more researchers have investigated high-volume fly ash concrete extensively in recent years. It was concluded that the strength development effect of hydraulic concrete is good, and all kinds of durability are excellent. Because it can markedly reduce the heat of hydration, concrete mixed with fly ash can also reduce the early-age cracking risk [6]-[8]. In this paper, through a lot of experiments, we studied the basic mechanics performance and shrinkage performance of concrete which influenced by the amount of fly-ash used in it, also we have also discussed the role of fly ash would play in the process of the strength increasing mechanism.

\section{RAW MATERIALS USED IN THE EXPERIMENTS}

The cement is P.O42.5 ordinary portland cement that produced by Tex xinjiang cement Co., Ltd. The fineness is $3.0 \%$, the soundness remains qualified, the initial-set time and final-set time are $146 \mathrm{~min}$ and $211 \mathrm{~min}$, the $3 \mathrm{~d}, 28 \mathrm{~d}$ compressive strength are $23.9 \mathrm{MPa}$ and $47.6 \mathrm{MPa}$, and the $3 \mathrm{~d}$, $28 \mathrm{~d}$ flexural strength respectively is $4.7 \mathrm{MPa}, 8.0 \mathrm{MPa}$. The fly-ash is 1 grade produced by Manasi power generation branch of Xinjiang Tianshan electric power company. The fineness is $9.22 \%$, the water demand ratio is $91 \%$, the loss on ignition is $5.24 \%$, the water content is $0.5 \%$ and the content of $\mathrm{SO} 3$ is $1.22 \%$. The specific surface area of slag is $4633 \mathrm{~m} 3 / \mathrm{kg}$, the chloride ion content is $0.0242 \%$, the loss on ignition is $1.236 \%$, the water content is $0.3 \%$ and the content of $\mathrm{SO} 3$ is $0.29 \%$. Using natural sand as fine aggregate, the fineness modulus is 2.8 , the stacking density is $1.651 \mathrm{~g} / \mathrm{cm} 3$, the apparent density is $2.626 \mathrm{~g} / \mathrm{cm} 3$, the mud content is 0 , the robustness is $0.4 \%$, and the $\mathrm{SO} 3$ content is $0.009 \%$. Using natural pebble of two different particle sizes as coarse aggregate, the particle sizes are $5 \sim 20 \mathrm{~mm}$ and $20 \sim 40 \mathrm{~mm}$, the 
apparent density are $2.275 \mathrm{~g} / \mathrm{cm} 3$ and $2.283 \mathrm{~g} / \mathrm{cm} 3$, the skin drying density are $2.719 \mathrm{~g} / \mathrm{cm} 3$ and $2.671 \mathrm{~g} / \mathrm{cm} 3$, the crushing value are $7.3 \%$ and $7.5 \%$, and the robustness is $4 \%$. Superplasticizer is used as admixture, produced by Xinjiang Hong Li new material factory. The water reducing efficiency is $14 \%$, the bleeding rate is $42 \%$ and the initial-set time and final-set time are $45 \mathrm{~min}$ and $100 \mathrm{~min}$. Water is local tap water, and all the measurement results of the above raw materials comply with the related standard [4] [9].

\section{TEST PROGRAM}

In this experiment, the apparent density hypothesis was used to produce $\mathrm{C} 30$ concrete, fly-ash content was $20 \%$, sand ratio was $35 \%$, and the gradation of coarse aggregate was 50\%:50\% and the water reducer content was $0.5 \%$ in the standard mixing proportion. Based on the standard mixing proportion, water consumption was kept unchanged and four kinds of water-binder ratio $(0.35,0.375,0.40,0.425)$, four kinds of content of fly ash $(5 \%, 10 \%, 15 \%, 20 \%)$, four kinds of content of slag $(5 \%, 10 \%, 15 \%, 20 \%)$, four kinds of sand ratio $(33 \%, 35 \%, 37 \%, 39 \%)$, four kinds of aggregate gradation $(30 \%: 70 \%, 40 \%: 60 \%, 50 \%: 50 \%, 60 \%: 40 \%)$ were selected to design 16 sets of experiment, which are cross experiment. The variation range of influence factors is showed in table 1 and the table of orthogonal design is showed in table 2.

The basic mechanical properties of each group were tested, including compressive strength tests, axial compressive tests, splitting tensile strength tests, flexural strength tests, elasticity modulus, drying shrinkage tests and Plastic shrink tests. The specification and amounts of test sample block were showed in table 3. All kinds of raw materials were mixed in the horizontal-axis forced mixer and then were poured into relevant test molds. After that, the molds were put on the vibration table to be vibrated. The vibration time was kept to be about 30s. The concrete blocks were stored in cool and ventilated place for $24 \mathrm{~h}$ after pouring and then put in the curing room for standard curing. Plastic shrinkage test sample block were immediately covered with plastic film, and the environment temperature was $30 \pm 1^{\circ} \mathrm{C}$ Celsius, the relative humidity was about $\pm 50 \pm 5 \%$; the plastic film was taken off two hours later, and then blowing the concrete surface by the fan, wind speed of $8 \mathrm{~m} / \mathrm{s}$; use a crack observation instrument and a ruler to record test block cracking time, crack number, crack length and width. In the first three hours, observe a time every 5 minutes; when the cracks were found, observe a time every 10 minutes; when the concrete surface appears cracks, to observe a time every 30 minutes; one day later, observe a time every 0.5 days until the age of 3 days [15].

TABLE I. THE VARIATION RANGE OF INFLUENCE FACTORS

\begin{tabular}{|c|c|c|c|c|c|}
\hline A & Water-binder ratio & 0.35 & 0.375 & 0.40 & 0.425 \\
\hline B & Content of fly ash & $5 \%$ & $10 \%$ & $15 \%$ & $20 \%$ \\
\hline C & Content of slag & $5 \%$ & $10 \%$ & $15 \%$ & $20 \%$ \\
\hline D & Sand ratio & $33 \%$ & $35 \%$ & $37 \%$ & $39 \%$ \\
\hline E & Aggregate gradation & $30 \%: 70 \%$ & $40 \%: 60 \%$ & $50 \%: 50 \%$ & $60 \%: 40 \%$ \\
\hline
\end{tabular}

TABLE II. THE TABLE OF ORTHOGONAL DESIGN

\begin{tabular}{|c|c|c|c|c|c|c|c|c|c|c|c|c|c|c|c|c|}
\hline Number & 1 & 2 & 3 & 4 & 5 & 6 & 7 & 8 & 9 & 10 & 11 & 12 & 13 & 14 & 15 & 16 \\
\hline A & A1 & A1 & A1 & A1 & $\mathrm{A} 2$ & A 2 & A2 & A2 & A3 & A3 & A3 & A3 & A4 & A4 & A4 & A4 \\
\hline B & B1 & B2 & B3 & B4 & B1 & B2 & B3 & B4 & B1 & B2 & B3 & B4 & B1 & B2 & B3 & B4 \\
\hline $\mathrm{C}$ & $\mathrm{C} 1$ & $\mathrm{C} 2$ & $\mathrm{C} 3$ & $\mathrm{C} 4$ & $\mathrm{C} 2$ & $\mathrm{C} 1$ & $\mathrm{C} 4$ & $\mathrm{C} 3$ & $\mathrm{C} 3$ & $\mathrm{C} 1$ & $\mathrm{C} 4$ & $\mathrm{C} 2$ & $\mathrm{C} 4$ & $\mathrm{C} 3$ & $\mathrm{C} 2$ & $\mathrm{C} 1$ \\
\hline D & D1 & D2 & D3 & D4 & D3 & D4 & D1 & D2 & D4 & D3 & D2 & D1 & D2 & D1 & D4 & D3 \\
\hline E & E1 & E2 & E3 & E4 & E4 & E3 & E2 & E1 & E2 & E1 & E4 & E3 & E3 & E4 & E1 & E2 \\
\hline \multicolumn{17}{|c|}{ TABLE III. } \\
\hline & & & & \multicolumn{5}{|c|}{ Text age/d } & \multicolumn{4}{|c|}{ Number of each age } & \multicolumn{4}{|c|}{ Specimen size /mm } \\
\hline \multicolumn{4}{|c|}{ compressive strength } & & \multicolumn{4}{|c|}{$1 \mathrm{~d}, 3 \mathrm{~d}, 7 \mathrm{~d}, 14 \mathrm{~d}, 28 \mathrm{~d}, 45 \mathrm{~d}$} & \multicolumn{4}{|c|}{3} & \multicolumn{3}{|c|}{$150 \times 150 \times 150$} & \\
\hline \multicolumn{5}{|c|}{ splitting tensile strength } & \multicolumn{4}{|c|}{$1 \mathrm{~d}, 3 \mathrm{~d}, 7 \mathrm{~d}, 14 \mathrm{~d}, 28 \mathrm{~d}, 45 \mathrm{~d}$} & \multicolumn{4}{|c|}{3} & \multicolumn{3}{|c|}{$150 \times 150 \times 150$} & \\
\hline \multicolumn{5}{|c|}{ rupture strength } & \multicolumn{4}{|c|}{$1 \mathrm{~d}, 3 \mathrm{~d}, 7 \mathrm{~d}, 14 \mathrm{~d}, 28 \mathrm{~d}, 45 \mathrm{~d}$} & \multicolumn{4}{|c|}{3} & \multicolumn{3}{|c|}{$150 \times 150 \times 550$} & \\
\hline \multicolumn{5}{|c|}{ axial compressive strength } & \multicolumn{4}{|c|}{$1 \mathrm{~d}, 3 \mathrm{~d}, 7 \mathrm{~d}, 14 \mathrm{~d}, 28 \mathrm{~d}, 45 \mathrm{~d}$} & \multicolumn{4}{|c|}{3} & \multicolumn{3}{|c|}{$150 \times 150 \times 300$} & \\
\hline \multicolumn{4}{|c|}{ elasticity modulus } & & \multicolumn{4}{|c|}{$1 \mathrm{~d}, 3 \mathrm{~d}, 7 \mathrm{~d}, 14 \mathrm{~d}, 28 \mathrm{~d}, 45 \mathrm{~d}$} & \multicolumn{4}{|c|}{3} & \multicolumn{3}{|c|}{$150 \times 150 \times 300$} & \\
\hline \multicolumn{4}{|c|}{ drying shrinkage tests } & & \multicolumn{4}{|c|}{$1 \mathrm{~d}, 3 \mathrm{~d}, 7 \mathrm{~d}, 14 \mathrm{~d}, 28 \mathrm{~d}, 45 \mathrm{~d}$} & \multicolumn{4}{|c|}{3} & \multicolumn{3}{|c|}{$150 \times 150 \times 515$} & \\
\hline \multicolumn{5}{|c|}{ plastic shrink tests } & \multicolumn{4}{|c|}{ I } & \multicolumn{4}{|c|}{2} & \multicolumn{3}{|c|}{$600 \times 600 \times 63$} & \\
\hline
\end{tabular}




\section{RESULTS AND ANALYSIS}

A. The Influence of Fly Ash on the Concrete Strength and Elasticity Modulus of Concrete

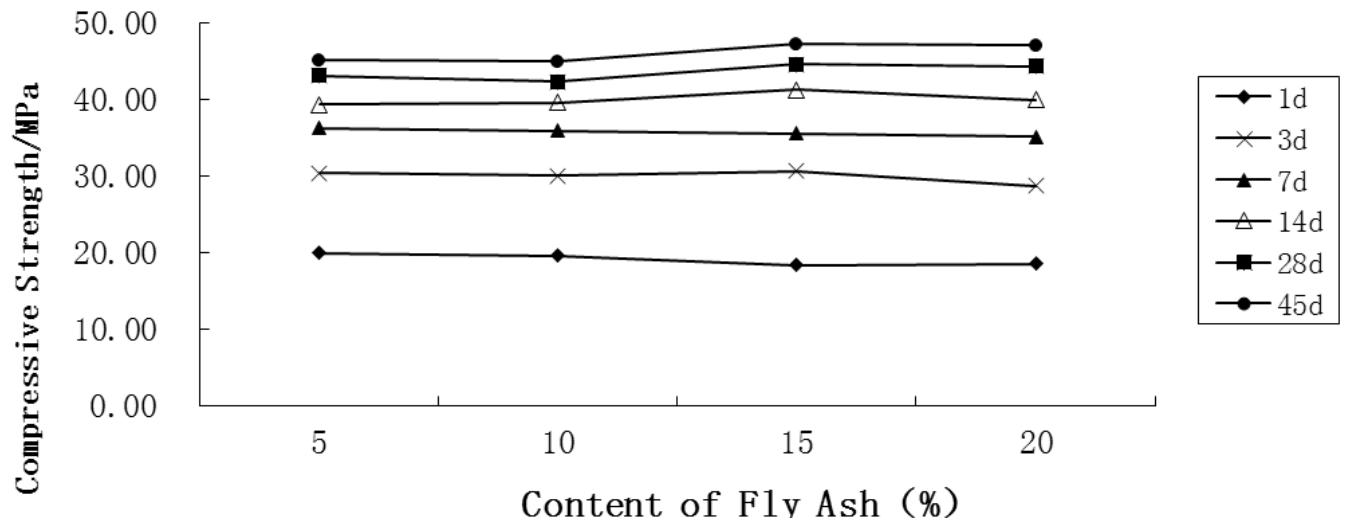

Figure 1. The influences of different contents of fly-ash on the compressive strength of concrete

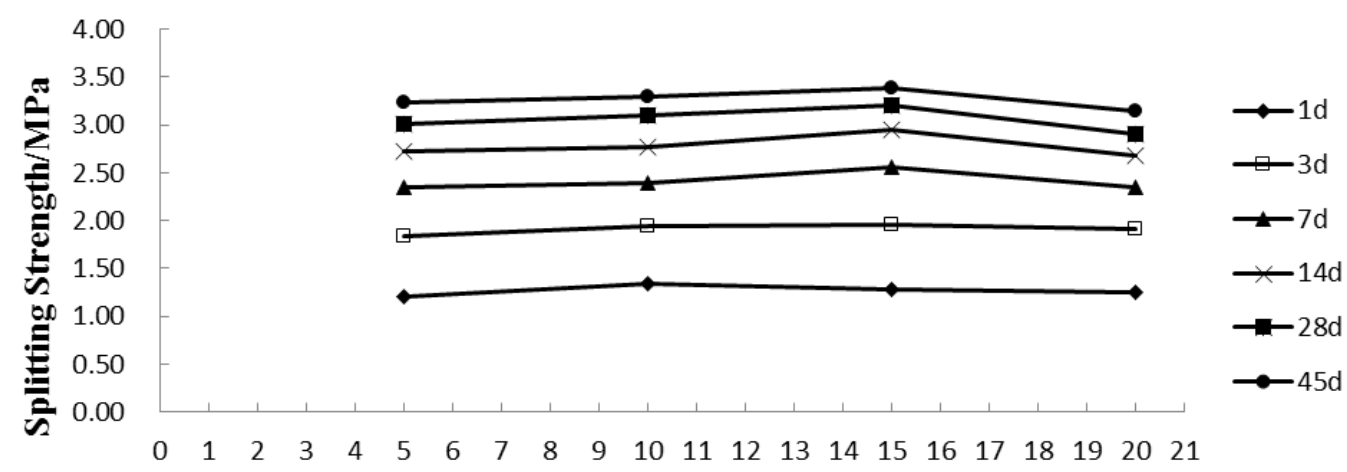

Conteent of Fly Aah (\%)

Figure 2. The influences of different contents of fly-ash on the splitting strength of concrete

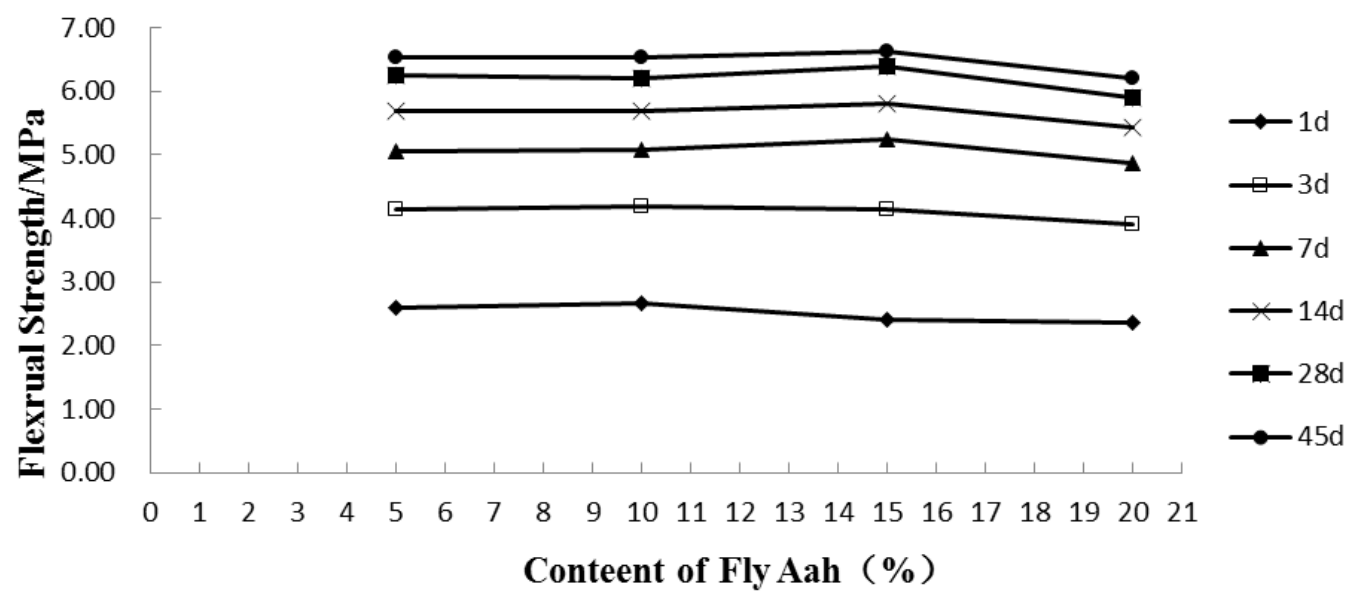

Figure 3. The influences of different contents of fly-ash on the flexural strength of concrete 


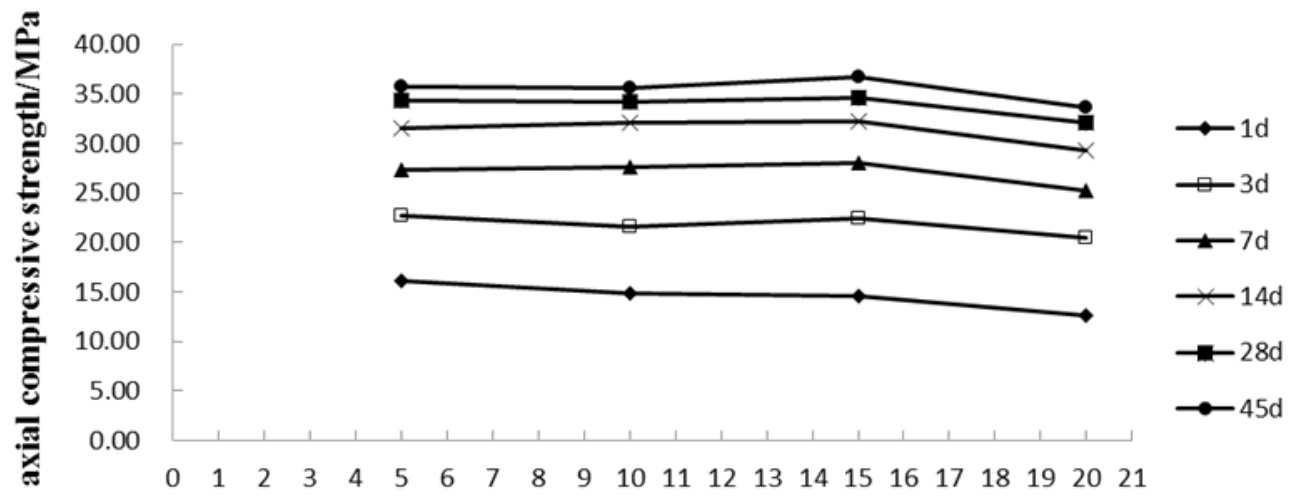

Content of Fly-ash

Figure 4. The influences of different contents of fly-ash on the axial compressive strength of concrete

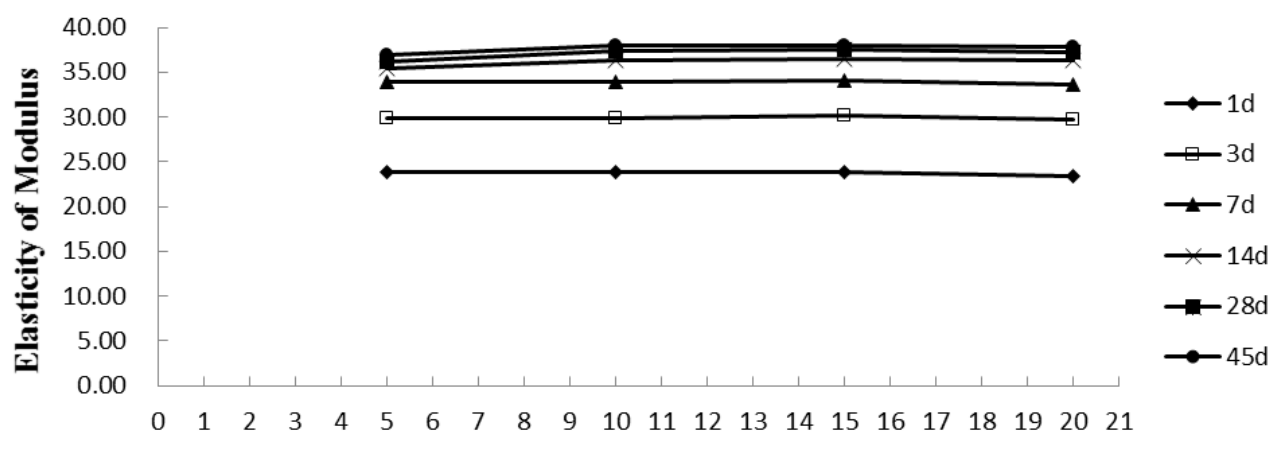

Content of Fly-ash

Figure 5. The influences of different contents of fly-ash on the elasticity modulus of concrete

The compressive strength, splitting tensile strength, flexural strength, axial compressive strength, elasticity modulus which arrived at the corresponding age were determined according to the test procedures., and the results were shown in Fig.1 Fig.5.

Fig. $1 \sim$ Fig.5 shows that when curing time increasing, the concrete strength (compressive strength, splitting tensile strength, flexural strength, axial compressive strength) and elasticity modulus increased gradually, but rather a gradual slowing of growth. Taking the compressive strength as an example, when the fly ash content is $15 \%$, the compressive strength of $1 \mathrm{~d}$ increased by $66.16 \%$ compared with that of $3 \mathrm{~d}$, the compressive strength of $7 \mathrm{~d}$ increased by $16.10 \%$ compared with that of $3 \mathrm{~d}$, the compressive strength of $14 \mathrm{~d}$ increased by $16.20 \%$ compared with that of $7 \mathrm{~d}$, the compressive strength of $28 \mathrm{~d}$ increased by $7.88 \%$ compared with that of $14 \mathrm{~d}$, the compressive strength of $45 \mathrm{~d}$ increased by $5.94 \%$ compared with that of $28 \mathrm{~d}$.
Fig. $1 \sim$ Fig.5 shows that compressive strength and axial compressive strength increased gradually along with the increase of the contents of fly ash at the age of $1 \mathrm{~d}, 3 \mathrm{~d}$ and 7 $\mathrm{d}$, but when the age is more than $7 \mathrm{~d}$,concrete strength have the tendency of increasing first and then decreasing. But on the whole, when the fly ash content reached $15 \%$, concrete strength and elasticity modulus reached the peak strength and elastic modulus of concrete. Taking the compressive strength as an example, comparing the concrete whose fly ash content is $5 \%$ and $15 \%$, if age is less than $7 \mathrm{~d}$ when the content is $15 \%$, the compressive strength is bigger than the amount of $15 \%$, which indicated that fly ash played a major role on the later period of concrete strength growth.

\section{B. The Influences of Fly-ash on the Shrinkage of Concrete}

According to the test procedure, drying shrinkage tests and Plastic shrink tests were determined were carried out respectively, and the results were shown in Fig.6 and Fig.7. 


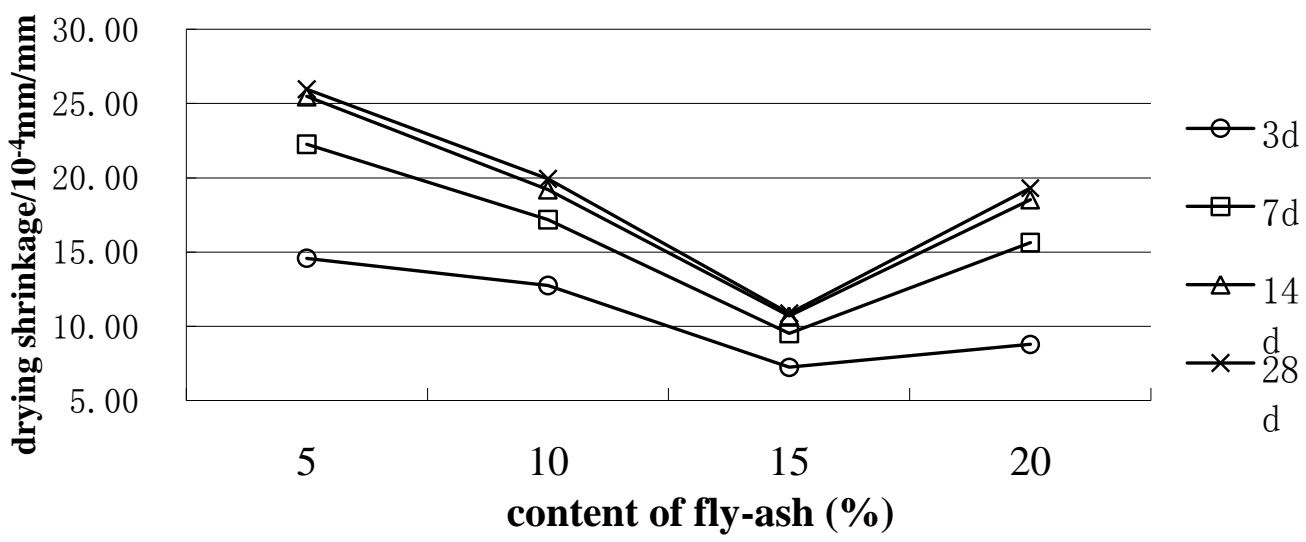

Figure 6. The influences of different contents of fly-ash on the drying shrinkage of concrete

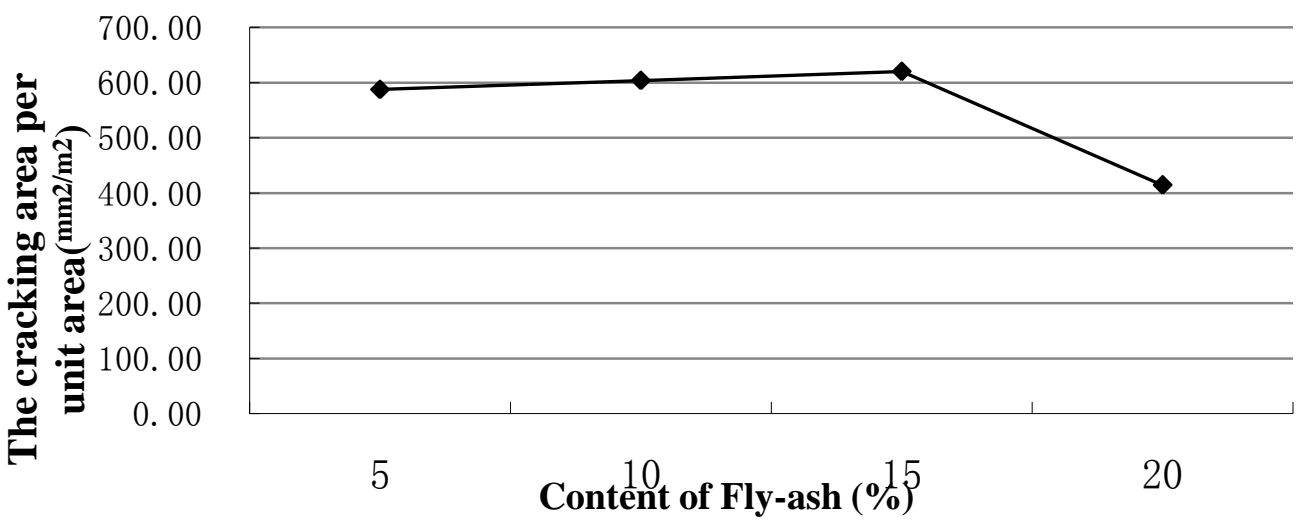

Figure 7. The influences of different contents of fly-ash on the plastic shrinkage of concrete

Fig.6 shows that although the curing age of concrete is different the concrete strength, But the shrinkage rate of concrete showed a trend of first increase and then decrease with the increase of fly ash content. Also taking $28 \mathrm{~d}$ as an example, When the fly ash content was $5 \%$, the shrinkage rate of concrete is $25.98 \times 10-4 \mathrm{~mm} / \mathrm{mm}$, whose dry shrinkage was the most obvious in the four kinds of contents; When the fly ash content was $15 \%$, the shrinkage rate of concrete is $10.87 \times 10-4 \mathrm{~mm} / \mathrm{mm}$, with a differential of $15.11 \times 10-4 \mathrm{~mm} / \mathrm{mm}$, and gap is the most significant. Comparing the concrete whose fly ash content is $5 \%$ and $15 \%$, if age is less than $7 \mathrm{~d}$ when the content is $15 \%$, the compressive strength is bigger than the amount of $15 \%$, which indicated that fly ash played a major role on the later period of concrete strength growth. When the fly ash content continued to increase to $20 \%$, the shrinkage rate of concrete is $19.30 \times 10-4 \mathrm{~mm} / \mathrm{mm}$, Although the shrinkage rate of concrete increased compared with the amount of $15 \%$, the effect was not obvious compared to the other two kinds of content. Fig.7 shows that the cracking area per unit area increased first and decreased afterwards with the increase of the contents of fly ash and the area of plastic cracking was smallest with the addition of $20 \%$ fly-ash. At the same time the change of the area of plastic cracking was not big, stick to the $15 \%$ as a baseline, the area of plastic cracking only decreased by $5.29 \%$ when the fly ash content is $5 \%$, but when the fly ash content increased to $20 \%$, stick to the $15 \%$ as a baseline, the area of plastic cracking only decreased by $33.19 \%$.

\section{MECHANISM ANALYSES}

The effect of fly ash on concrete strength is mainly due to "pozzolanic effect", "morphological effect" and "micro aggregate effect", which respectively produce three kinds of potential energy: "pozzolanic effect" makes fly ash have activation potential energy, "morphological effect" produces water reducing potential energy and "micro aggregate effect" produces compacting potential energy [12]. The activated substances in the fly ash could react with the cement hydration products $\mathrm{Ca}(\mathrm{OH}) 2$, this reaction produces new kind of gel material, namely C-S-H. This kind of new material could not only fill the void in the set cement to improve the mechanical properties of concrete, enhance the strength between the set cement and every kinds of component in the concrete to improve the interface bond strength but also improve the structural integrity, which plays an active role in the growth of the compressive strength of concrete. However the water-binder ratio 
decreases with the content of fly slag increases, which reduces the formation of $\mathrm{Ca}(\mathrm{OH}) 2$ caused by the hydration reaction. This lead to the result that the cement hydration products is too poor to react with the fly ash in the later stage, thus the strength does not increase but decrease instead. In addition, when the curing age is $1 \mathrm{~d} \sim 7 \mathrm{~d}$, the $\mathrm{C}-\mathrm{S}-\mathrm{H}$ gel formed by the two reaction of fly ash will be attached to the fly ash particles, forming a non compacting structure. That structure not only slows down the reaction rate of fly ash, but also reduces the density of concrete, which leads to the low early strength of concrete. With the growth of age, the $\mathrm{Ca}(\mathrm{OH}) 2$ and fly ash in concrete continue to react, the active substances in fly ash can be decomposed gradually, which can increase the hydration reaction and the reaction rate, and form a large number of hydration products which can improve the strength of concrete. Therefore, when the age is more than $7 \mathrm{~d}$, fly ash began to play a role; the influence of the content change on the concrete strength is gradually increasing.

In dry shrinkage test of concrete, as the particles fly ash particles was smaller, the porosity of cement is improved after mixing with fly ash, which could enhance the destiny and strength of concrete and reduce the amount of cement used in cementing materials, indirectly reduce hydration degree of concrete internal and the heat of hydration. At the same time, the fly ash can react with the hydration products of cement to generate a new cementing material, which can further fill the void of cement stone, reduce concrete internal moisture loss, to inhibit the contraction of the slurry. But when the fly ash content is excessive, it will have a surplus after improving cement graded, due to the particles is less than the cement particles, the same amount of fly ash replacing cement will make pores of cement paste increased slightly, leading to the shrinkage rate of concrete increased slightly when the fly ash content is $20 \%$.

In shrinkage test of concrete, as the particles fly ash particles was smaller, the porosity of cement is improved after mixing with fly ash, which could enhance the destiny and strength of concrete. And then slow down the rate of water inside the concrete upward migration, concrete internal moisture to the migration. But when the fly ash content is excessive, the cement content in the concrete decreased which is not conducive to the hydration reaction of cement and will reduce the concrete autogenous shrinkage, while increasing the free water content and making up for insufficiency of free water upward migration. When the fly ash content is up to $20 \%$, the area of plastic cracking of concrete decreased.

\section{CONCLUSIONS}

The late strength of concrete can be greatly improved by mixing fly ash into concrete. Index of basic mechanical properties of concrete increases first and then decreases with the increasing of the fly ash content, when the fly ash content is $15 \%$, the basic mechanical properties of concrete is best, and fly ash will play a main role in the late age of concrete strength increasing.
The mixing of fly ash plays an important role in reducing the drying shrinkage of concrete. The mixing of fly ash can reduce the dry shrinkage of concrete, and the shrinkage of concrete decreases with the increase of the fly ash content, but the shrinkage value will increase slightly when the content is more than $15 \%$.

The mixing of fly ash plays an important role in reducing the plastic cracking. However, with the increase of the content of fly ash, the degree of plastic shrinkage will be increased first and then decreased, and the inhibition effect on the plastic cracking of concrete is best when the fly ash content is $20 \%$.

\section{REFERENCES}

[1] Liu Chunlin. Effect of Fly Ash Replacement to Performance of C50 Concrete Using in Bridge [J].Low Temperature Architecture Technology, 2009(7):13-15.

[2] Yue-Hong Han, Liaoqun, Cailu.Characteristics and application of high volume fly ash concrete [J]. The quality of the project, 2009(7):13-15.

[3] Zhang Xiaowei, Xiao Ruimin, Effect of fly ash content on shrinkage of concrete and its mechanism [J]. China Concrete and Cement Products, 2005(4).

[4] Qiao Fengjiao. Research on the Shrinkage Ability of High Performance Concrete Added Fly Ash [D]. Harbin: Harbin industrial university master's degree thesis, 2007.

[5] Huang Bo. Testing Research on Physical and Mechanical Performance of High Fly Ash Content Concrete [D]. A thesis submitted to Zhengzhou University for the degree of Master, 2012.

[6] Dhir R K., Byars E., Amir-Latifi S A. PFA concrete: strength development of RHPC/PFA blends [J]. Pub Struct Eng, 1993, 71(8/20); 139-145.

[7] Mccarthy M J., Dhir R K., Development of high volume fly ash cements for use in concrete construction [J]. Fuel, 2005(84):1423-1432.

[8] Swmay R N., Hung H., Engineering properties of high volume fly Ash concrete [A]. In Fly Ash, Silica Fume, Slag \& Natural Pozzolans in Concrete [C]. Proceedings Sixth CANMET/ACI international Conference, Bangkok, Thailand, 1998: 331-359.

[9] National Standards of P. R. Common Portland Cement (GB 175-2007) [S]. Beijing: National Cement Standardization Technical Committee (SAC/TC 184), 2007.

[10] National Standards of P. R. Fly Ash Used For Cement and Concrete (GB/T 1596-2005) [S]. Beijing: National cement Standardization Technical Committee (SAC/TC 184), 2005.

[11] National Standards of P. R. Ground Granulated Blast Furnace Slag Used For Cement And Concrete (GB/T 18046-2008) [S]. Beijing: National Cement Standardization Technical Committee (SAC/TC 184), 2008.

[12] National Standards of P. R. Sand for Construction (GB/T 14684-2011) [S]. Beijing: National Cement Standardization Technical Committee (SAC/TC 184), 2011.

[13] National Standards of P. R. Pebble and Crushed Stone for Construction (GB/T 14685-2011) [S]. Beijing: National Cement Standardization Technical Committee (SAC/TC 184), 2011.

[14] National Standards of P. R. Concrete Admixtures (GB 8076-1997) [S]. 1997.

[15] China civil engineering society standard. Durability design and construction guidelines of concrete structures (CCES 01, 2004) [S]. Beijing: China Construction Industry Press, 2005.

[16] Yang Quanhua, Li Wenwei. Research and Application of Hydraulic Concrete [M]. Beijing: China Water \& Power Press, 2005. 